Encontro Nacional de

Economia Industrial e Inovação
Indústria e Desenvolvimento Econômico:

desafios e perspectivas

18 a 20 de setembro de 2018

Uberlândia - Minas Gerais

\title{
Evolução estrutural e setorial de emprego nas Microrregiões Brasileiras: uma Análise Exploratória para o período 2003-2013 pelo método shift-share ${ }^{1}$
}

Thiago Caliari

Professor Adjunto III (Instituto Tecnológico de Aeronáutica - ITA)

Ulisses Pereira dos Santos

Professor Adjunto A (CEDEPLAR/FACE/UFMG)

\section{Resumo}

O período compreendido entre os anos de 2003 e 2013 é marcado por uma redução do desemprego a nível nacional, focado principalmente no crescimento da demanda do setor externo, da demanda de camadas inferiores de renda e de investimentos públicos em infraestrutura e habitação. Assim, esse trabalho procurou analisar a evolução do emprego a nível microrregional através do método shiftshare, buscando padrões regionais diferenciados na explicação da evolução do emprego formal no Brasil. Os resultados encontrados apresentam redução da desigualdade regional, com crescimento relativo maior para as regiões norte, nordeste e centro-oeste. Os setores que mais contribuíram a nível nacional para esse incremento foram comércio, serviços e construção civil, sendo ainda importantes a administração pública para as regiões norte e nordeste e o setor agropecuária, extração vegetal, caça e pesca para a região centro-oeste. Conclui-se que o padrão de crescimento do emprego pode ter reduzido a desigualdade, mas com especialização em setores de baixo dinamismo e transbordamento setorial.

Palavras-chave: economia regional, estrutura do emprego, microrregiões, dinamismo setorial, shiftshare.

\section{Abstract}

The period between 2003 and 2013 is marked by a reduction in unemployment in national level, mainly focused on demand growth from foreign trade and lower income families and from public investments in infrastructure and housing. So, this work aims to analyze the evolution of employment at the microregional level through the shift-share method, seeking different regional patterns for Brazil. The results show a reduction of regional inequality, with a higher relative growth for the North, Northeast and Center-west regions. The main economic sectors for this result were trade, services and civil construction. Public administration for North and Northeast regions and 'Agricultural, livestock, forest products, hunting and fishing' for the Central-west region are still important. We conclude that the pattern of employment growth may have reduced inequality, but with a specialization in economic sectors with low dynamism and low sectoral spillovers.

Key-words: regional economics, employment structure, microrregions, sectoral dynamism, shiftshare.

JEL: R11, L6, L7, L8

Área ABEIN: 4.2 Economias Regionais e Urbanas

\footnotetext{
${ }^{1}$ Os autores agradecem à Fundação de Amparo à Pesquisa do Estado de São Paulo (FAPESP) pelo suporte financeiro para apresentação do artigo no congresso.
} 
Encontro Nacional de

Economia Industrial e Inovação
Indústria e Desenvolvimento Econômico:

desafios e perspectivas

18 a 20 de setembro de 2018

Uberlândia - Minas Gerais

Evolução estrutural e setorial de emprego nas Microrregiões Brasileiras: uma Análise Exploratória para o período 2003-2013

\section{Introdução}

Segundo dados do Instituto de Pesquisa Econômica Aplicada (IPEA) ${ }^{2}$, a taxa de desemprego no Brasil passou de $14.1 \%$ em 2003 para 7.8\% em 2013, sendo esse processo pautado por uma ampliação no grau de formalização do trabalho no país (Remy, Queiroz, e Filho 2011). Essa importante redução, depois de um período de oscilações macroeconômicas, vem sendo estudada e debatida dentro da academia brasileira. Em suma, a explicação que é premente parte do ciclo de valorização das commodities no mercado internacional (SESSA et al, 2017) - com o aumento da demanda asiática, principalmente na China - e o aumento da demanda interna fruto das políticas de distribuição de renda do governo - que criaram nova demanda a partir do acesso aos mercados por uma faixa da população que antes se posicionava em condições de pobreza críticas - (SILVEIRA NETO e AZZONI, 2013) e o financiamento estatal em projetos de infraestrutura e habitacionais, representados principalmente nos Programas de Aceleração do Crescimento (PAC 1 em 2007 e PAC 2 em 2010), na Política de Desenvolvimento Produtivo (PDP em 2008) e no Plano Brasil Maior (PBM em 2011). Tais questões levaram a um crescimento médio do PIB de $3.6 \%$ a.a. no período de 2003 a 2013, com resultados importantes no desenvolvimento econômico com estabilidade de preços, distribuição de renda e inclusão social (CURADO, 2011). Porém, nesse ínterim, indagações e críticas tem sido levantadas sobre a impossibilidade desse crescimento ser sustentável a longo prazo, dado questões relacionadas à doença holandesa (BRESSER-PEREIRA, 2008), à desindustrialização (OREIRO e FEIJÓ, 2010) e aos limites do padrão de crescimento via demanda. Julga-se parte desse período - os anos do governo Lula - até como um 'nacional-desenvolvimentismo às avessas'(GONÇALVES, 2012) ou um embate entre convenções distintas de desenvolvimento (estabilizadora e neodesenvolvimentista) (ERBER, 2011).

Em um contexto regional, mas não desconexo, surge a necessidade de se entender e dirimir problemas relacionados ao desenvolvimento desigual nacional. Nessa toada, o período é marcado também por políticas com esse objetivo; em 2003 foi lançado o Plano Nacional de Desenvolvimento Regional (PNDR I), revigorado em 2012 (PNDR II) (RESENDE et al., 2015), e em conjunção a essa política, outras a nível federal - como programas de universalização e regionalização do ensino superior -, estadual e municipal são praticadas (complementares ou não) com vistas a buscar a redução da desigualdade. Esse processo - de pensamento da necessidade de um desenvolvimento econômico regional - contribuiu para a ampliação da abrangência territorial do sistema brasileiro de inovação, dotando um conjunto de localidades fora do eixo regional mais desenvolvido do país de infraestrutura de ensino superior e pesquisa (SANTOS, 2017). Dentre os resultados esperados para esse processo, se destacariam o aumento da oferta de trabalho qualificado e a consequente ampliação da massa salarial.

Ainda, o formato de atuação de algumas políticas federais horizontais - notadamente o Bolsa Família, entre outros - teve o perfil de impactar em maior escala nas regiões menos favorecidas, sendo portanto um vetor importante de redução de desigualdades (SILVEIRA NETO e AZZONI, 2013).

\footnotetext{
${ }^{2}$ Informações disponíveis em http://www.ipeadata.gov.br/Default.aspx. Acesso em 11/04/2017.
} 
No entanto, ao pensar em redução de desigualdade, o vetor mais importante de análise é o emprego. Nesse sentido, é a remuneração do fator trabalho que se apresenta como a principal fonte de renda de populações menos favorecidas, e por isso é um indicador importante da evolução das disparidades regionais. Porém, o incremento do trabalho e renda não deve ser visto como um fim único; esse fim não pode ser desprovido de um aparato que o sustente e permita sua evolução contínua e sustentada. Antes disso, a evolução da capacitação econômica de uma região deve ser vista como um conjunto de ações, políticas, instituições e atores que permitam, ao longo do tempo, que o desenvolvimento possa ser cada vez mais resiliente.

Ademais, as mudanças na estrutura da economia mundial a partir da década de 1970 alteraram o caráter das políticas de desenvolvimento regional. A ascensão de um modelo marcado pela competição global baseada em vantagens comparativas dinâmicas, ou seja, aquelas baseadas sobretudo em conhecimento indicou a necessidade da criação de infraestruturas de aprendizado com o objetivo de promoção do desenvolvimento regional (ASHEIM, 1996). Integrariam tais infraestruturas organizações orientadas para o ensino técnico e tecnológico, para a pesquisa, para o financiamento e para a transferência de tecnologia. Estas organizações, associadas a uma aglomeração produtiva local, constituiriam sistemas regionais de inovação (SRI) (COOKE, 1992). Estes sistemas seriam os indutores da competitividade e, consequentemente, do desenvolvimento regional.

Em conjunção a esse paradigma, o desenvolvimento econômico é associado às atividades produtivas de transformação industrial (KALDOR, 1957; VERDOORN, 1956; VERDOORN, 1980) e, cada vez mais, entendido conexo à evolução da complexidade econômica na base de atividades de uma região/nação (HAUSMANN et al., 2011). Há uma associação inequívoca entre as capacitações adquiridas por uma sociedade e a sua capacidade de intensificar a agregação de valor, o aumento da produtividade e a geração de serviços complexos. No caso da economia brasileira, trabalhos mostram a importância dos setores industriais no Brasil no que tange a seus encadeamentos (transbordamentos produtivos e tecnológicos à jusante e à montante) (SESSO FILHO et al., 2010), bem como a validade da lei de Kaldor-Verdoorn ${ }^{3}$ para distintos períodos da econômica nacional (MARINHO; NOGUEIRA; ROSA, 2002; MORRONE, 2013) ${ }^{4}$.

Isso posto, o objetivo desse trabalho é fazer uma análise exploratória da evolução do emprego a nível microrregional no Brasil, destacando a evolução do período 2003-2013. Em suma, procuramos responder a seguinte pergunta: a evolução da composição setorial microrregional de emprego no Brasil é um componente importante da redução da desigualdade regional? Para responder essa indagação será utilizada a metodologia shift-share para microrregiões brasileiras, com composição setorial definida por classificação IBGE. A análise pretende ser exploratória, com o intuito de captar a evolução do emprego e os principais vetores setoriais para a redução das disparidades regionais, mas não se abstendo de dirimir opiniões relacionadas à capacitação regional para o desenvolvimento de longo prazo. Assim, uma segunda pergunta que se mostra premente é: a evolução do emprego é sustentável para o desenvolvimento econômico de longo prazo, considerando a importância do incremento da complexidade econômica?

A busca de respostas para essas perguntas se dará à luz das mudanças estruturais e regionais na economia brasileira ao longo das últimas décadas. Nesse sentido, é destacável o processo de relocalização da indústria no território do país, intensificado ao longo da década de 1990 e mantido ao longo da década de 2000, sem, contudo (DINIZ, 1993; SABOIA, 2013). Outro aspecto que irá permear a análise que segue diz respeito ao processo de redução da importância relativa da indústria de transformação para o conjunto da indústria nacional. Observou-se ao longo das décadas de 1990 e 2000 uma redução do peso do setor para os principais indicadores conjunturais analisáveis, como o

\footnotetext{
${ }^{3}$ A lei de Kaldor-Verdoorn indica que o crescimento da produtividade total de um país é relacionado ao aumento das atividades da indústria de transformação, pelas economias estáticas e dinâmicas de escala dessas atividades.

${ }^{4} \mathrm{O}$ trabalho de Morrone (2013), mais recente, encontra validade para a lei no caso brasileiro, mas destaca que 'os resultados são inferiores aos observados para o Brasil em períodos anteriores, demonstrando a queda da dinâmica industrial no período analisado'.
} 
emprego, o PIB e as exportações setoriais (CANO, 2012). Verificam-se, portanto, dois fenômenos relacionados à indústria, que ocorrem concomitantemente que apresentam grandes impactos sobre a estrutura do emprego regional no Brasil, a redução da representatividade do setor e a sua reorientação locacional. Perante a esses processos a literatura aponta para o aumento da importância do setor de serviços nos grandes centros urbanos do país, como aponta Saboia (2013), e dos setores primários (produção agrícola e extrativa mineral), como observado por Cano (2012). Nesse sentido, a avaliação das mudanças na estrutura do emprego para o conjunto da economia brasileira acaba por tangenciar uma série de fenômenos recentes, os quais não podem ser ignorados e que implicam na dinâmica dos dados a serem apresentados na sequência.

Esse trabalho está dividido em 4 seções, a contar essa introdução. Na segunda seção são apresentados indicadores agregados por setor, com vistas a aprofundar o entendimento da dinâmica nacional de emprego, bem como a remuneração e demais variáveis. Na seção 3 são discutidos os resultados obtidos pelo método shift-share para as microrregiões, fechando a análise com as considerações finais.

\section{Emprego e renda no Brasil - evolução dos indicadores agregados por setor}

Como informações iniciais são apresentadas a evolução do emprego e remuneração do trabalho para o conjunto dos dados nacionais, seguindo o período compreendido entre 2003 e 2013. A classificação setorial utilizada para a análise - e que será seguida durante todo o artigo - é a setorialização do Instituto Brasileiro de Geografia e Estatística (IBGE), definida em oito rubricas, a saber: '1. extrativa mineral', '2. indústria de transformação', '3. serviços industriais de utilidade pública', '4. construção civil', '5. comércio', '6. serviços', '7. administração pública' e '8. agropecuária, extração vegetal, caça e pesca'. Os dados foram obtidos no sítio da Relação Anual de Informações Sociais disponibilizada pelo Ministério do Trabalho e Emprego (Rais-MTE).

As primeiras informações - Tabela 1 - dizem respeito à participação setorial no total de empregos e número de empregos por setor IBGE. Conforme pode ser depreendido, o setor 'serviços' é o maior empregador da economia brasileira, apresentando um aumento da participação no emprego de $31.7 \%$ em 2003 para $34.2 \%$ em 2013 com um incremento de $78.3 \%$ no total de empregados no período, maior que a média de $65.7 \%$. Este dado indica a continuidade de uma das mudanças mais importantes na estrutura do emprego no brasil ao longo das últimas décadas, que pode ter sido diretamente impactado entre 2003 e 2013 pelo quadro de liberalização comercial, iniciado ainda na década de 1990, e pela apreciação cambial observada nesse período (CANO, 2012; DE PAULI; NAKABASHI; SAMPAIO, 2012).

Os demais setores que aumentaram sua participação no total de empregos foram 'comércio', 'construção civil' e 'extrativa mineral', todos frutos do aumento acima da média no número de empregados, reflexo esse do impulso econômico desses setores na economia brasileira durante o período considerado. No caso do setor 'comércio', o incremento no emprego pode ser atrelado ao modelo de crescimento adotado no Brasil, especialmente a partir de 2007, com base no incentivo ao crescimento da demanda interna por meio de estímulos ao consumo (políticas de renda e crédito). Como resultado, esse setor foi o principal responsável pelo crescimento econômico brasileiro ao longo do período aqui avaliado (JACINTO e RIBEIRO, 2015). O setor 'construção civil' também se beneficiou de programas de governo, com foco em segmentos como habitação e infraestrutura, enquanto o setor 'extrativa mineral' foi diretamente impactado pelo aquecimento da demanda internacional por commodities e pela consequente melhora nos preços externos. 
Tabela 1 -Empregos por setor IBGE, total e porcentagem (2003-2013)

\begin{tabular}{|c|c|c|c|c|c|c|c|}
\hline Setores & 2003 & 2005 & 2007 & 2009 & 2011 & 2013 & $\begin{array}{c}\Delta \text { total } \\
(2013 / 2003)\end{array}$ \\
\hline Extrativa Mineral & 122.806 & 147.560 & 185.444 & 208.836 & 231.389 & 261.383 & $112.8 \%$ \\
\hline \% Extrativa mineral & $0.4 \%$ & $0.4 \%$ & $0.5 \%$ & $0.5 \%$ & $0.5 \%$ & $0.5 \%$ & \\
\hline Indústria transform. & 5.356 .159 & 6.133 .461 & 7.082 .167 & 7.361 .084 & 8.113 .805 & 8.292 .739 & $54.8 \%$ \\
\hline \% Indústria transform. & $18.1 \%$ & $18.5 \%$ & $18.8 \%$ & $17.9 \%$ & $17.5 \%$ & $16.9 \%$ & \\
\hline Serv industriais & 319.068 & 341.989 & 364.665 & 385.379 & 412.741 & 444.674 & $39.4 \%$ \\
\hline$\%$ Serv Industriais & $1.1 \%$ & $1.0 \%$ & $1.0 \%$ & $0.9 \%$ & $0.9 \%$ & $0.9 \%$ & \\
\hline Const Civil & 1.048 .251 & 1.245 .395 & 1.617 .989 & 2.132 .288 & 2.750 .173 & 2.892 .557 & $175.9 \%$ \\
\hline$\%$ Const Civil & $3.5 \%$ & $3.7 \%$ & $4.3 \%$ & $5.2 \%$ & $5.9 \%$ & $5.9 \%$ & \\
\hline Comércio & 5.119 .479 & 6.005 .187 & 6.840 .915 & 7.692 .951 & 8.842 .677 & 9.511 .094 & $85.8 \%$ \\
\hline \% comércio & $17.3 \%$ & $18.1 \%$ & $18.2 \%$ & $18.7 \%$ & $19.1 \%$ & $19.4 \%$ & \\
\hline Serviços & 9.378 .566 & 10.510 .761 & 11.935 .780 & 13.235 .389 & 15.372 .455 & 16.726 .013 & $78.3 \%$ \\
\hline \% Serviços & $31.7 \%$ & $31.6 \%$ & $31.7 \%$ & $32.1 \%$ & $33.2 \%$ & $34.2 \%$ & \\
\hline Admin. Pública & 6.991 .973 & 7.543.939 & 8.198 .396 & 8.763 .970 & 9.103 .601 & 9.340 .409 & $33.6 \%$ \\
\hline \% Admin. Pública & $23.7 \%$ & $22.7 \%$ & $21.8 \%$ & $21.3 \%$ & $19.7 \%$ & $19.1 \%$ & \\
\hline Agrop, ext vegetal, caça e pesca & 1.207 .670 & 1.310 .320 & 1.382 .070 & 1.427 .649 & 1.483 .790 & 1.479 .564 & $22.5 \%$ \\
\hline$\%$ Agro, ext, caça e pesca & $4.1 \%$ & $3.9 \%$ & $3.7 \%$ & $3.5 \%$ & $3.2 \%$ & $3.0 \%$ & \\
\hline Total & 29.543 .972 & 33.238 .612 & 37.607 .426 & 41.207 .546 & 46.310 .631 & 48.948 .433 & $65.7 \%$ \\
\hline
\end{tabular}

Fonte: Elaboração própria a partir de dados da RAIS-MTE. 
É importante destacar também que a rubrica 'comércio' passa a ser o segundo maior setor em número de empregados em 2013, com queda de participação da 'administração pública; conjuntamente, comércio e serviços respondiam em 2013 pelo total de $53.6 \%$ da mão-de-obra formal empregada no Brasil. O aumento da representatividade do setor comércio em termos de emprego deve ser observada com certa dose de ceticismo, uma vez que se trata de um setor de baixa produtividade do trabalho, convertida em baixa remuneração individual, como será observado a seguir (JACINTO e RIBEIRO, 2015).

O setor 'indústria de transformação' apresenta declínio na participação total de empregos, um indicador de um processo de desindustrialização (ROWTHORN e RAMASWAMY, 1998). Esta é, porém, uma pequena redução, concomitante ao aumento no número de empregados abaixo da média nacional. Cabe destacar que há um movimento de queda no emprego industrial observado desde o início da década de 1990, assim como também é observado para a participação desse setor na produção e nas exportações nacionais (CANO 2012; PAULI, NAKABASHI e SAMPAIO, 2012). Fatores como a liberalização comercial, a sobrevalorização cambial, as altas taxas de juros domésticos com a consequente redução do investimento industrial estariam associados a essa perda de representatividade da indústria de transformação na composição geral do emprego formal no país.

Adicionalmente, apresenta-se abaixo a evolução do salário médio real dos trabalhadores. As séries de salário médio tiveram os valores deflacionados para reais de 2015 com o uso do Índice de Preços ao Consumidor Amplo (IPCA-IBGE), disponível no sítio do IPEADATA.

Figura 1 - Evolução do Salário Real - média Setores IBGE (R\$ de 2015)

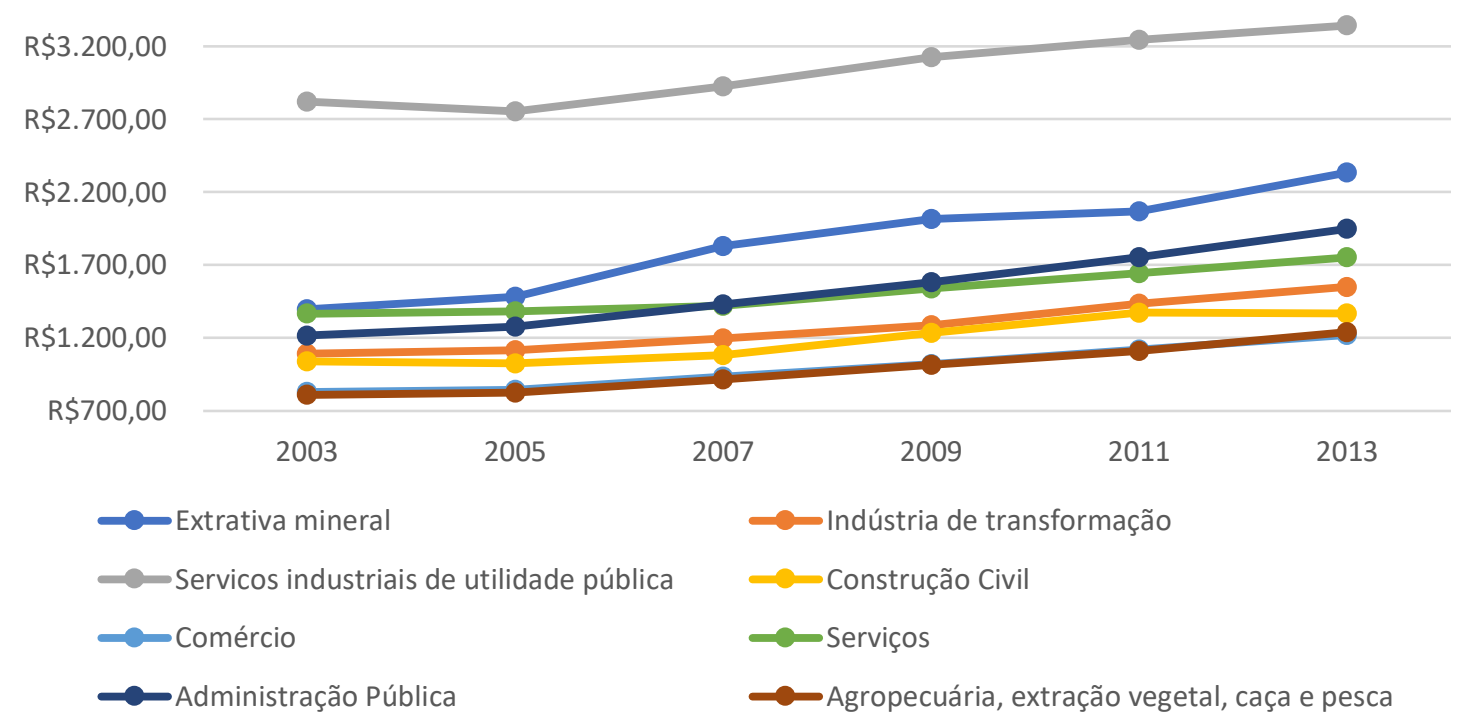

Fonte: Elaboração própria a partir de dados da RAIS-MTE.

Em suma, o aumento real dos salários para todos os setores sofre impacto da política de valorização do salário mínimo seguida pelo governo federal durante o período. Esse impacto também pode ser mensurado pelo aumento da participação da remuneração salário no PIB nacional, que passou de 36.1\% em 2005 para 45.0\% em 2013 (FILHO e PAULA, 2016).

A remuneração média do setor IBGE 'serviços industriais de utilidade pública' foi durante todo o período superior a todos os demais setores, mas foi também a que teve menor percentual de aumento do salário real (18.5\%). Mesmo assim, ainda manteve uma diferença da ordem de $43 \%$ em relação à remuneração real média do segundo setor ('extrativa mineral').

Além disso, um crescimento considerável da rubrica 'extrativa mineral' e a mudança de posicionamento entre 'administração pública' e 'serviços' pode ser destacada. No caso da indústria extrativa mineral, há que se salientar a demanda por trabalho qualificado (técnico e superior) e a alta produtividade do setor no Brasil, que permitem compreender como seu crescimento resultou em progressos consideráveis em termos de remuneração (JACINTO e RIBEIRO, 2015). Para a 
administração pública, a demanda por trabalho qualificado também é um elemento explicativo para a evolução das remunerações.

Uma observação importante da análise conjunta da evolução da quantidade de empregos e do salário real médio se relaciona ao fato de o aumento da participação da mão-de-obra empregada em comércio e serviços ser seguida por um crescimento real menor dos salários nessas rubricas. $\mathrm{O}$ ‘comércio' apresenta o menor salário real médio em 2013 (R\$ 1220.9), e o setor serviços apresenta a segunda menor taxa de crescimento $(28.3 \%)$. Este aspecto pode ser creditado à baixa produtividade do setor de comércio e em boa parte dos sub-setores que compõem a rubrica serviços no Brasil ${ }^{5}$ (ARBACHE, 2015). Destaca-se que esse resultado ocorre a despeito de ter o setor serviços se notabilizado pelo aumento no emprego de trabalhadores com formação superior nos últimos anos (PAULI, NAKABASHI e SAMPAIO, 2012).

Ainda, além da política de valorização do salário mínimo, o aumento observado do salário real deve ser analisado em conjunção à modificação no perfil educacional dos trabalhadores, expresso pela variação da proporção de trabalhadores com ensino superior, mestrado e doutorado. Essas informações são apresentadas na Tabela 2.

O período de análise não é compatível porque a desagregação da escolaridade na RAIS-MTE só é disponibilizada para dados a partir de 2006, mas mesmo assim existe uma relação entre o incremento de salário real e da proporção de trabalhadores com maior escolaridade. No próprio caso da classificação 'serviços industriais de utilidade pública', o menor incremento de salário real está associado ao menor incremento na escolaridade dos trabalhadores.

Os valores observados para economia brasileira apontam para um quadro que, a grosso modo, tem sido discutido no ambiente acadêmico. Suas principais características são: (i) a evolução dos salários acima da inflação (consagrado pelos sucessivos aumentos reais do salário mínimo e seu impacto na economia); (ii) o aumento da importância dos setores de 'construção civil', 'comércio' e 'serviços' em detrimento do seu baixo dinamismo econômico, expresso em aumentos menores dos salários reais; (iii) o aumento da proporção de trabalhadores com ensino superior, mestrado e doutorado, que tem estreita ligação com as políticas de acesso ao ensino superior estabelecidas nos governos Lula (2003-2010) e Dilma (2010-2016) (PINHO e ZAN, 2013; BRASIL, 2015).

Todavia, para o presente trabalho essa discussão preliminar deve servir como um 'pano de fundo' para um contexto mais específico, buscando uma análise microrregional da evolução do emprego, o que será feito na próxima seção.

\footnotetext{
${ }^{5}$ Jacinto e Ribeiro (2015) mostram que a produtividade dos serviços cresceu durante o período 2000-2009, pautado principalmente em serviços às empresas. Porém, serviços especializados e que tem perfil de maior produtividade (P\&D; Projetos; consultorias; financeiros) são menos representativos no país como um todo.
} 
Tabela 2 - Número de trabalhadores total; Número de trabalhadores com ensino superior, mestrado e doutorado

\begin{tabular}{|c|c|c|c|c|c|c|c|c|}
\hline \multirow[b]{2}{*}{ Setores IBGE } & \multicolumn{3}{|c|}{2006} & \multicolumn{3}{|c|}{2013} & \multirow{2}{*}{$\begin{array}{l}\text { Variação \% } \\
\text { trabalhadores } \\
\text { com ensino } \\
\text { superior, } \\
\text { mestrado e } \\
\text { doutorado } \\
(2006-2013)\end{array}$} & \multirow[b]{2}{*}{$\begin{array}{l}\text { Variação no } \\
\text { salário real } \\
(2003-2013)\end{array}$} \\
\hline & $\begin{array}{l}\text { superior, } \\
\text { mestrado e } \\
\text { doutorado } \\
\text { (1) }\end{array}$ & Total (2) & (1) / (2) & $\begin{array}{l}\text { superior, } \\
\text { mestrado e } \\
\text { doutorado } \\
\text { (3) }\end{array}$ & Total (4) & (3) / (4) & & \\
\hline Extrativa mineral & 28.570 & 183.188 & $15.6 \%$ & 57.089 & 261.383 & $21.8 \%$ & $40.0 \%$ & $67.1 \%$ \\
\hline Indústria de transformação & 394.734 & 6.594 .783 & $6.0 \%$ & 716.467 & 8.292 .739 & $8.6 \%$ & $44.3 \%$ & $41.9 \%$ \\
\hline $\begin{array}{l}\text { Serviços industriais de utilidade } \\
\text { pública }\end{array}$ & 55.635 & 344.563 & $16.1 \%$ & 81.981 & 444.674 & $18.4 \%$ & $14.2 \%$ & $18.5 \%$ \\
\hline Construção Civil & 55.301 & 1.393 .446 & $4.0 \%$ & 145.210 & 2.892 .557 & $5.0 \%$ & $26.5 \%$ & $42.8 \%$ \\
\hline Comércio & 266.268 & 6.330 .337 & $4.2 \%$ & 566.687 & 9.511 .094 & $6.0 \%$ & $41.7 \%$ & $47.2 \%$ \\
\hline Serviços & 1.990 .620 & 11.229 .881 & $17.7 \%$ & 3.518 .566 & 16.726 .013 & $21.0 \%$ & $18.7 \%$ & $28.3 \%$ \\
\hline Administração Pública & 2.451 .836 & 7.721 .815 & $31.8 \%$ & 3.916 .519 & 9.340 .409 & $41.9 \%$ & $32.1 \%$ & $60.0 \%$ \\
\hline $\begin{array}{l}\text { Agropecuária, extração vegetal, } \\
\text { caça e pesca }\end{array}$ & 23.642 & 1.357 .230 & $1.7 \%$ & 44.181 & 1.479 .564 & $3.0 \%$ & $71.4 \%$ & $53.2 \%$ \\
\hline Total & 5.266 .606 & 35.155 .243 & $15.0 \%$ & 9.046 .700 & 48.948 .433 & $18.5 \%$ & $23.4 \%$ & $48.7 \%$ \\
\hline
\end{tabular}

Fonte: Elaboração própria a partir de dados da RAIS-MTE. 


\section{A evolução do emprego nas microrregiões brasileiras a partir do método shift-share}

Para analisar a evolução do emprego nas microrregiões brasileiras optou-se nesse trabalho pela análise da estrutura setorial de emprego através do método shift-share (SIMÕES, 2005), inserindo o aperfeiçoamento proposto por Esteban-Marquillas (1972).

Especificamente, o método pretende identificar e desagregar os componentes do crescimento do emprego em uma análise descritiva da estrutura econômica por componentes que destacam (i) o dinamismo setorial na criação de empregos (efeito estrutural - EE), resultante da sua composição estrutural com setores que cresceram mais do que na média nacional; (ii) as (des)vantagens locacionais (efeito diferencial - D), sendo que o valor positivo (negativo) que a região j conseguirá é em razão da taxa de crescimento em determinado(s) setor(es) ser maior (menor) nesta região do que na média nacional; (iii) a observação da especialização regional em setores que possui maior vantagem competitiva (efeito alocação - A).

Da soma desses três efeitos tem-se a Variação Líquida Total (VLT), que indica o montante líquido de emprego que determinada microrregião obteve entre o ano inicial e final da análise. As equações para cada componente são conforme abaixo.

$V L T=E E+D+A$

$V L T=E_{i j}^{0}\left(e_{i}-e\right)+\left(2 E_{i j}^{0}-E_{i j}^{0 *}-E_{i j}^{t}+E_{i j}^{t *}\right)\left(e_{i j}-e_{i}\right)+\left(E_{i j}^{t}-E_{i j}^{t *}-E_{i j}^{0}+E_{i j}^{0 *}\right)\left(e_{i j}-e_{i}\right)$

Em Que:

$E_{i j}^{0}=$ emprego do setor $i$ da região $j$ no ano base (2003);

$E_{i j}^{t}=$ emprego do setor $i$ da região $j$ no ano final (2013);

$e=$ taxa de crescimento do emprego nacional;

$e_{i}=$ taxa nacional de crescimento do emprego no setor $i$;

$e_{i j}=$ taxa de crescimento do emprego no setor $i$ na região $j$;

$E_{i j}^{(0 / t) *}=$ emprego esperado ou homotético no ano base/final, dado pela expressão:

$E_{i j}^{(0 / t) *}=E_{j}^{(0 / t)}\left(E_{i}^{(0 / t)} / E^{(0 / t)}\right)$

Sendo:

$E_{j}^{(0 / t)}=$ emprego total da região $j$ no ano base/final;

$E_{i}^{(0 / t)}=$ emprego total do setor $i$ no ano base/final;

$E^{(0 / t)}=$ emprego total nacional no ano base/final.

Se o VLT é negativo, há perda líquida de emprego durante os períodos; se positivo, o contrário é verdadeiro. Os anos de comparação da análise serão os anos de 2003 e 2013, considerando as 558 microrregiões do território brasileiro.

Catorze resultados distintos são possíveis a partir da consideração da VLT, considerando as distintas combinações dos efeitos EE, D e A. O extremo satisfatório da análise corresponde ao caso que apresenta resultados positivos para os três componentes da classificação da estrutura setorial. Nesse caso, pode-se considerar que a microrregião cresceu pelo dinamismo da estrutura setorial e incrementou suas vantagens locacionais, mas não há uma definição exata ainda sobre os resultados do efeito alocação, visto que uma microrregião pode ter valor positivo desse efeito se for especializada em setores com rápido crescimento $(++=+)$ ou não especializada em setores pouco competitivos $(--++)$ (ESTEBAN-MARQUILLAS, 1972), conforme apresentado no Quadro abaixo. Um tratamento específico considerando apenas o caso de vantagem competitiva especializada será utilizado para contornar esse problema quando feitas as análises. 
Quadro 2 - Resultados do Efeito Alocação

\begin{tabular}{lccc}
\hline \multicolumn{1}{c}{ Definição } & Efeito Alocação & Especialização & $\begin{array}{c}\text { Vantagem } \\
\text { Competitiva }\end{array}$ \\
\hline Desvantagem competitiva especializada & - & + & - \\
Desvantagem competitiva não especializada & + & - & - \\
Vantagem competitiva não especializada & - & + & + \\
Vantagem competitiva especializada & + & + & + \\
\hline
\end{tabular}

Fonte: Souza (2009).

Nossa análise não será baseada sobre os quatorze possíveis resultados (desses quatorze, doze são encontrados no uso da técnica, o que torna a comparação bastante complicada para o tamanho do artigo). Ao invés disso vamos adotar o critério de análise dos VLTs por quartis positivos e negativos, incluindo 3 quartis para VLTs negativos e 3 quartis para VLTs positivos (utilizaremos essa classificação para fazer comparações sobre emprego, renda e demais variáveis socioeconômicas) e análise dos efeitos estrutural, diferencial e alocação com vantagem competitiva especializada em cada microrregião.

Como primeira informação apresentamos a figura abaixo do mapa brasileiro microrregional com a distribuição por classificação dos resultados VLT, seguido da Tabela descritiva com esses resultados e alguns destaques.

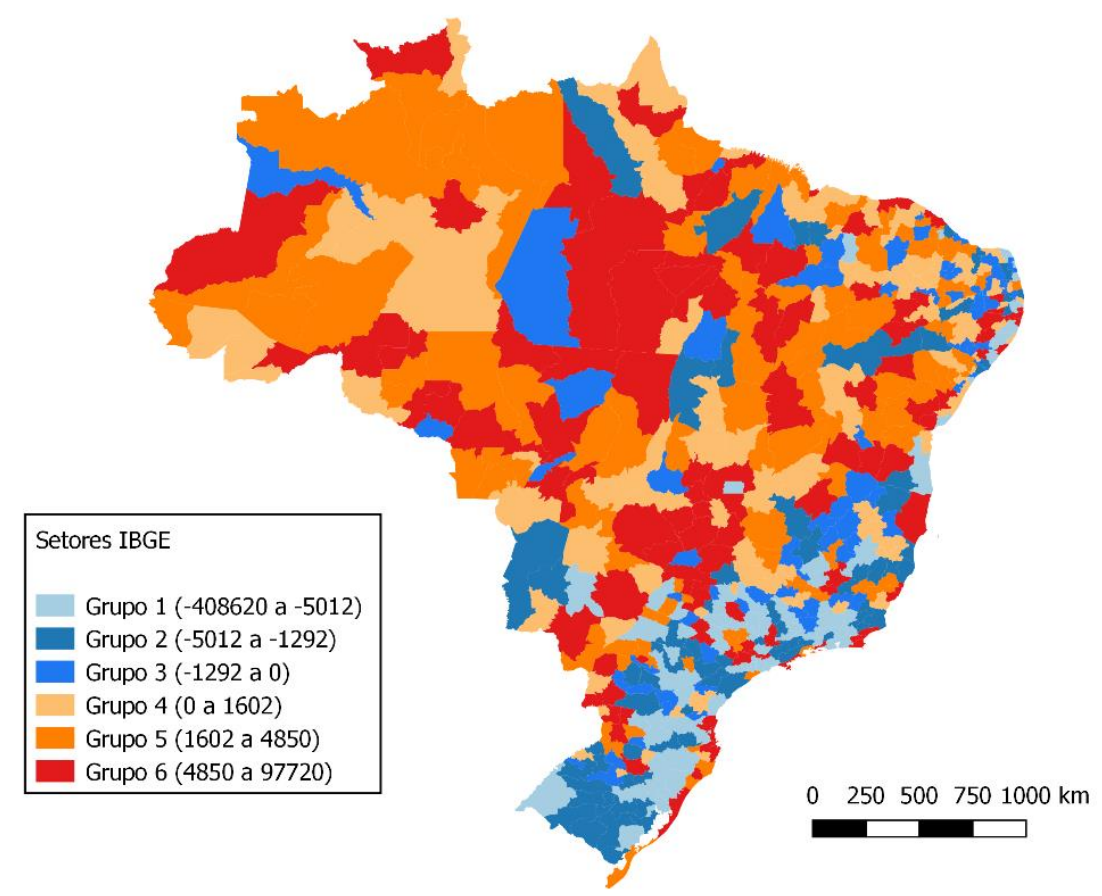

Figura 2 - Brasil - Microrregiões segundo valores de VLT

Fonte: Elaboração própria.

Tabela 3 - Classificação VLT e Regiões Federativas

\begin{tabular}{l|c|c|c|c|c|c}
\hline \multicolumn{1}{c}{ Valores VLT } & \multirow{2}{*}{ Frequência } & \multicolumn{5}{c}{ Região Federativa } \\
\cline { 3 - 6 } & 78 & & NE & SE & S & CO \\
\hline $\begin{array}{l}\text { Grupo 1 (-408620.7 a - } \\
\text { 5010.4) }\end{array}$ & 78 & 4 & 13 & 41 & 22 & 2 \\
\hline Grupo 2 (-5005.5 a -1314.9) & 77 & 5 & 33 & 24 & 12 & 3 \\
\hline Grupo 3 (-1293.5 a 0) & 109 & 16 & 52 & 19 & 8 & 14 \\
\hline Grupo 4 (0 a 1550.2) & 108 & 19 & 43 & 21 & 12 & 13 \\
\hline Grupo 5 (1659.9 a 4772.1) & 108 & 20 & 33 & 23 & 14 & 18 \\
\hline Grupo 6 (4849.8 a 97720.2) & & & & & & 2 \\
\hline
\end{tabular}




\begin{tabular}{l|c|c|c|c|c|c} 
Total & $\mathbf{5 5 8}$ & $\mathbf{6 4}$ & $\mathbf{1 8 8}$ & $\mathbf{1 6 0}$ & $\mathbf{9 4}$ & $\mathbf{5 2}$ \\
\hline \% VLT Positivo & & $85.9 \%$ & $68.1 \%$ & $39.4 \%$ & $36.2 \%$ & $86.5 \%$ \\
\hline \% VLT Negativo & & $14.1 \%$ & $31.9 \%$ & $60.6 \%$ & $63.8 \%$ & $13.5 \%$ \\
\hline
\end{tabular}

Fonte: Elaboração própria.

Em linhas gerais, verifica-se que a maioria das microrregiões brasileiras $(58,2 \%)$ apresentaram resultados de VLT positivos no período considerado; justamente por esse motivo os grupos com microrregiões que tiveram VLT positivo são maiores (grupos 4 a 6). Na observação das regiões federativas, diferença significativa é verificada nos valores percentuais de VLTs. As regiões norte e centro-oeste são as que mais possuem microrregiões com VLT positivo, com resultados bastante superiores às demais. Em menor escala mas ainda acima da média pode-se verificar que os resultados comparativos também são válidos em favor da região nordeste, que possuiu $68,1 \%$ das microrregiões com VLT positivo. A observação do mapa é conclusiva nesse resultado, indo além: os resultados de VLT positivos na região nordeste são consistentemente relevantes no interior dessas regiões. É notório que a porção litorânea até o Rio Grande do Norte concentra resultados de VLT negativo.

Dessa forma, em um contexto ainda bastante geral, um primeiro resultado verificado pelo método diferencial-estrutural é o ganho comparativo de empregos em favor de regiões do interior do território nacional. Esse resultado está em acordo com estudos referentes às décadas de 1990 e 2000, especialmente para o emprego industrial (CANO, 2012; DINIZ, 1993)

A Tabela 4 apresenta informações sobre emprego, renda, variáveis socioeconômicas e educacionais, com resultados interessantes em relação às disparidades entre os grupos. Em relação à remuneração média, os grupos extremos - grupos 1 e 6 - possuem os maiores valores tanto em 2003 quanto em 2013. O crescimento de grupos intermediários - grupos 3, 4 e 5 - é, porém, maior, o que permite afirmar sobre uma diminuição nas disparidades médias salariais. Essa observação é interessante se comparada à população média dessas microrregiões. Novamente, observa-se populações médias maiores nos extremos dos grupos, sendo os demais compatíveis com valores muito próximos de média. Em suma, a consideração conjunta desses resultados permite salientar uma diminuição da disparidade a nível de escala regional, com incrementos maiores de salário para microrregiões de menor escala populacional e econômica.

O grupo 1 está associado a um perfil de microrregiões maiores, com diminuição comparativa de seu tamanho econômico visto o menor crescimento dos salários, empregos, PIB e PIB per capita em relação aos demais grupos. São regiões que já possuem escala econômica relevante e entram, possivelmente, em um horizonte de deseconomias de escala (já que tais regiões apresentam em média valores negativos elevados de efeito diferencial - média de -38792.5 -, este associado às desvantagens locacionais). O grupo 2 parece abarcar um conjunto de microrregiões medianas - aproximadamente 220 mil habitantes em 2013 - que vislumbra um menor crescimento das capacidades econômicas e de sua população. Esse pensamento também é válido para o Grupo 3, mas com um perfil de tamanho um pouco menor - 158 mil habitantes.

Comparativamente, esses três grupos apresentam um padrão de crescimento do emprego menor que as demais regiões, e esses resultados também são válidos para o crescimento das demais variáveis comparadas (com exceção de remuneração e acesso ao ensino superior para o Grupo 3, acima da média nacional).

Nos grupos 4 e 5 encontramos microrregiões com porte populacional próximo às microrregiões do grupo 3, mas que obtiveram crescimento maior no número de empregados, no PIB e no PIB per capita (e por isso mesmo se diferenciaram, possuindo VLT positivo). No grupo 6 temos microrregiões de porte médio a grande, com população de aproximadamente 555 mil habitantes em 2013, e que obtiveram os maiores crescimentos em número de empregados, população e PIB, mas não em PIB per capita, remuneração média e acesso ao ensino superior. São regiões, portanto, que cresceram fortemente em valores totais, mas que não apresentaram os melhores resultados em valores relativos. 
Tabela 4 - Variáveis selecionadas segundo Grupo VLT

\begin{tabular}{|c|c|c|c|c|c|c|c|c|}
\hline Variáveis & Anos & Grupo 1 & Grupo 2 & Grupo 3 & Grupo 4 & Grupo 5 & Grupo 6 & Total \\
\hline \multirow{2}{*}{ Remun. Média (R\$) } & 2003 & 1.407 & 1.168 & 923 & 920 & 992 & 1.280 & 1.107 \\
\hline & 2013 & 1.864 & 1.662 & 1.463 & 1.472 & 1.550 & 1.876 & 1.645 \\
\hline$\Delta$ Remun. Média (\%) & & $32.5 \%$ & $42.3 \%$ & $58.6 \%$ & $60.0 \%$ & $56.2 \%$ & $46.6 \%$ & $48.7 \%$ \\
\hline \multirow{2}{*}{ Média empregados } & 2003 & 196.407 & 27.493 & 14.537 & 15.634 & 15.167 & 70.927 & 53.021 \\
\hline & 2013 & 298.753 & 42.751 & 23.463 & 26.890 & 27.993 & 135.421 & 87.856 \\
\hline$\Delta$ Média empregados (\%) & & $52.1 \%$ & $55.5 \%$ & $61.4 \%$ & $72.0 \%$ & $84.6 \%$ & $90.9 \%$ & $65.7 \%$ \\
\hline \multirow{2}{*}{ População } & 2003 & 847.721 & 199.178 & 145.861 & 142.574 & 167.647 & 463.950 & 316.564 \\
\hline & 2013 & 954.186 & 219.429 & 158.393 & 161.355 & 190.196 & 554.420 & 361.549 \\
\hline$\Delta$ População (\%) & & $12.6 \%$ & $10.2 \%$ & $8.6 \%$ & $13.2 \%$ & $13.5 \%$ & $19.5 \%$ & $14.2 \%$ \\
\hline \multirow{2}{*}{ PIB (milhares R\$) } & 2003 & 22.100 & 3.442 & 1.503 & 1.801 & 1.896 & 8.074 & 6.063 .580 \\
\hline & 2013 & 35.900 & 5.973 & 2.491 & 3.509 & 3.499 & 16.400 & 10.700 .000 \\
\hline$\Delta \mathrm{PIB}(\%)$ & & $62.4 \%$ & $73.6 \%$ & $65.7 \%$ & $94.8 \%$ & $84.5 \%$ & $103.1 \%$ & $76.5 \%$ \\
\hline \multirow{2}{*}{ PIB per capita ( $R \$$ ) } & 2003 & 19.678 & 15.563 & 10.012 & 9.819 & 11.356 & 17.568 & 13.824 \\
\hline & 2013 & 28.085 & 22.917 & 15.343 & 17.921 & 17.839 & 29.970 & 22.001 \\
\hline$\Delta$ PIB per capita (\%) & & $42.7 \%$ & $47.3 \%$ & $53.2 \%$ & $82.5 \%$ & $57.1 \%$ & $70.6 \%$ & $59.2 \%$ \\
\hline \multirow{2}{*}{$\begin{array}{l}\text { \% da população com ensino superior } \\
\text { ou acima }\end{array}$} & 2003 & 0.109 & 0.100 & 0.097 & 0.095 & 0.086 & 0.100 & 0.097 \\
\hline & 2013 & 0.142 & 0.144 & 0.162 & 0.168 & 0.150 & 0.147 & 0.153 \\
\hline$\Delta$ Ensino Superior ou acima (\%) & & $30.6 \%$ & $43.8 \%$ & $65.9 \%$ & $76.8 \%$ & $75.2 \%$ & $47.2 \%$ & $57.1 \%$ \\
\hline
\end{tabular}


A Tabela 5 abaixo busca captar, na média, os principais determinantes para os resultados dos VLTs dos grupos considerados. Como pode-se depreender, os resultados são bastante distintos e, para alguns efeitos, bastante próximos em grupos com VLTs muito distintos. Tomamos o cuidado de incluir em uma coluna alternativa os resultados médios por grupo apenas para o efeito alocação vantagem competitiva especializada $(++=+)$, considerando então apenas os setores em que as microrregiões são especializadas e que cresceram acima da média nacional.

\section{Tabela 5 - Valores médios VLT, EE, D, A e Vantagem Competitiva Especializada, segundo Grupo} VLT

\begin{tabular}{c|c|c|c|c|c}
\hline Grupos & $\begin{array}{c}\text { Efeito } \\
\text { estrutural } \\
\text { (EE) }\end{array}$ & $\begin{array}{c}\text { Efeito } \\
\text { diferencial } \\
\text { (D) }\end{array}$ & $\begin{array}{c}\text { Efeito } \\
\text { alocação (A) } \\
\text { total }\end{array}$ & VLT & $\begin{array}{c}\text { Efeito Alocação } \\
\text { Vantagem } \\
\text { Compet } \\
\text { especializada }\end{array}$ \\
\hline 1 & 3337.5 & -38792.5 & 8698.5 & -26756.6 & 3646.7 \\
2 & -1379.3 & -24273.8 & 22868.8 & -2802.6 & 22096.3 \\
3 & -979.5 & -2247.3 & 2590.4 & -636.4 & 2190.7 \\
4 & -573.6 & -1101.7 & 2380.2 & 704.9 & 2939.6 \\
5 & -861.4 & -6220.6 & 9943.6 & 2861.6 & 12237.2 \\
6 & 724.5 & -43780.1 & 61247.8 & 18179.0 & 66602.0 \\
\hline
\end{tabular}

Fonte: Elaboração própria.

Por exemplo, o efeito estrutural apresenta-se positivo apenas para os grupos 1 e 6 . Isso significa que, na média, as microrregiões que tiveram os VLTs no extremo positivo e no extremo negativo têm composição setorial com maior peso dos setores que mais crescem na média nacional. Os resultados para essas regiões continuam a ser próximos quando comparados os valores para o efeito diferencial, que destacam as vantagens locacionais regionais. Nesse caso, as microrregiões possuem valores negativos altos, o que indica uma composição interna com setores que crescem abaixo da média nacional (ou seja, apesar de ter uma composição setorial que cresce muito no Brasil, internamente tem crescido pouco nessas regiões).

O que as diferencia de maneira clara é o efeito alocação; nesse caso, o ganho das microrregiões do grupo 6 é maior na comparação nacional, o que permitiu que tais localidades pudessem se posicionar no extremo superior do $\mathrm{VLT}^{6}$. É interessante verificar que para o conjunto total das médias dos grupos o efeito diferencial tem valores negativos e o efeito alocação tem valores positivos. Isso não significa, porém, que todas as microrregiões seguiram a média; na contagem total, 225 microrregiões tiveram efeito diferencial positivo e 101 microrregiões tiveram efeito alocação negativo. Mesmo assim, um padrão é passível de destaque: a maioria das microrregiões tem setores crescendo abaixo da média nacional (considerando o efeito diferencial negativo para 333 microrregiões, 59,7\% do total).

Há de se destacar também a comparação entre o efeito alocação total e efeito alocação competitiva especializada: caso o último seja maior que o primeiro, significa que foi importante para elevar a média total (e portanto apresentou maior importância que desvantagem competitiva não especializada). $\mathrm{O}$ contrário também é verdadeiro. Notadamente, a definição vantagem competitiva especializada teve impacto forte no efeito alocação total dos grupos com VLT positivo, sendo o contrário para os demais grupos.

Uma análise microrregional dos setores que mais contribuíram para o VLT positivo - Figura 4 que os mais relevantes são o setor comércio, que tem o maior VLT positivo em 33,5\% das microrregiões (187) e o segundo maior VLT positivo em outras 38,2\% (213) das microrregiões. É seguido pelo setor serviços, que responde por ter o primeiro VLT positivo em 19,7\% (110) e o segundo VLT positivo em $19,4 \%$ (108) microrregiões, pelo setor construção civil $(16,7 \% \text { e } 11,0 \%)^{7}$, indústria de transformação

\footnotetext{
${ }^{6}$ Apesar das microrregiões do grupo 1 também alcançarem efeito alocação positivo, não foi suficiente para dirimir o valor negativo do efeito diferencial.

${ }^{7}$ A hierarquização setorial foi estabelecida considerando o primeiro e segundo valor positivo do VLT. Utilizaremos essa ordem também na comparação para os demais efeitos.
} 
(12,0\% e 15,1\%), administração pública $(5,0 \%$ e 11,8\%), agropecuária, extração vegetal, caça e pesca $(4,8 \%$ e $3,2 \%)$, extrativa mineral $(6,3 \%$ e $0,9 \%)$ e serviços industrias de utilidade pública $(1,8 \%$ e $0,5 \%)$.
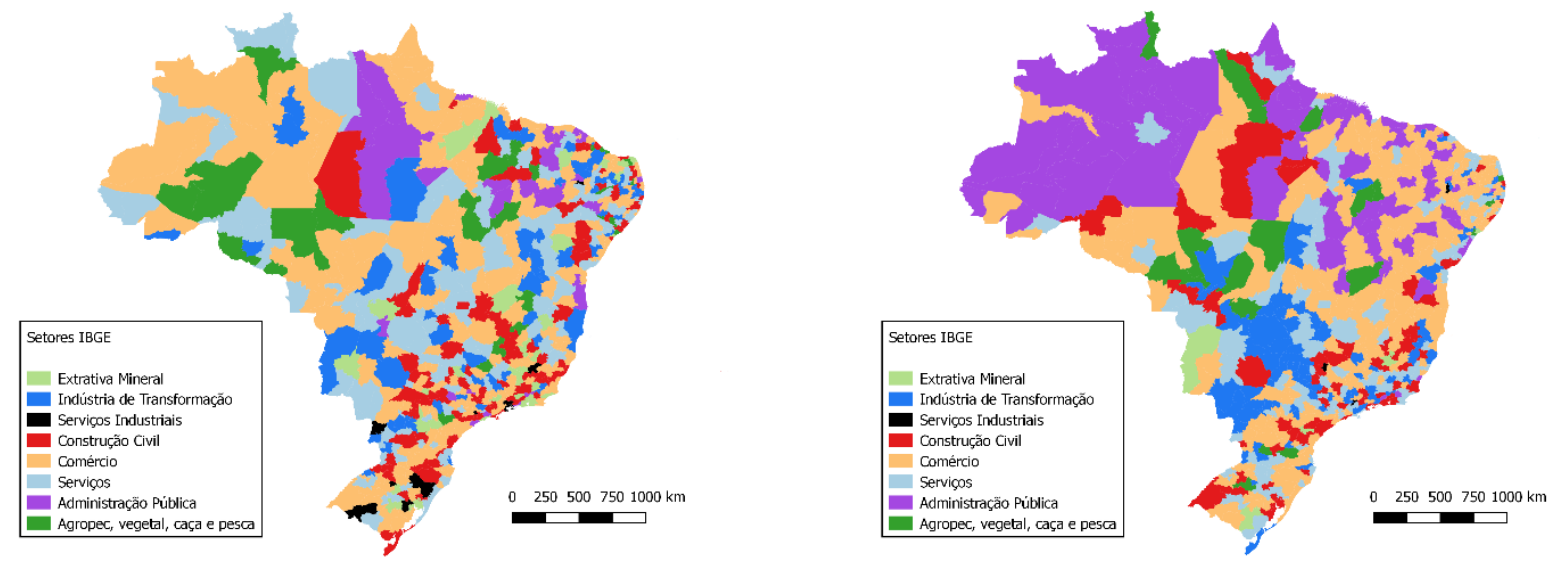

\section{3a. Primeiro Setor}

3b. Segundo setor

Figura 3. Setores com maior variação positiva no VLT - microrregiões

Fonte: Elaboração própria.

A análise detalhada dos principais setores com valor positivo para cada efeito do método diferencial/estrutural pode ser proveitoso para uma análise mais minuciosa do impacto desses setores nas microrregiões comparadas. O primeiro efeito analisado na Figura 5 - efeito estrutural (EE) - mostra que os setores com maior variação positiva são comércio $(63,8 \%$ e $23,5 \%)$, construção civil $(22,9 \%$ e $20,6 \%)$, serviços $(11,1 \%$ e $53,1 \%)$ e extrativa mineral $(2,1 \%$ e $2,9 \%)$. Reconsiderando, vale relembrar que o efeito estrutural é positivo quando a microrregião é especializada em setores da economia nacional que apresentam altas taxas de crescimento, acima da média nacional.

Assim, o resultado mostra que o efeito estrutural segue em linha com o crescimento desses setores no total nacional - conforme explicitado na Figura 1 e Tabela $1-$, com participação principal do setor comércio que, apesar de não ser o setor com maior crescimento percentual no total de emprego nacional, foi o principal setor responsável pelo efeito estrutural positivo na grande maioria das microrregiões brasileiras.
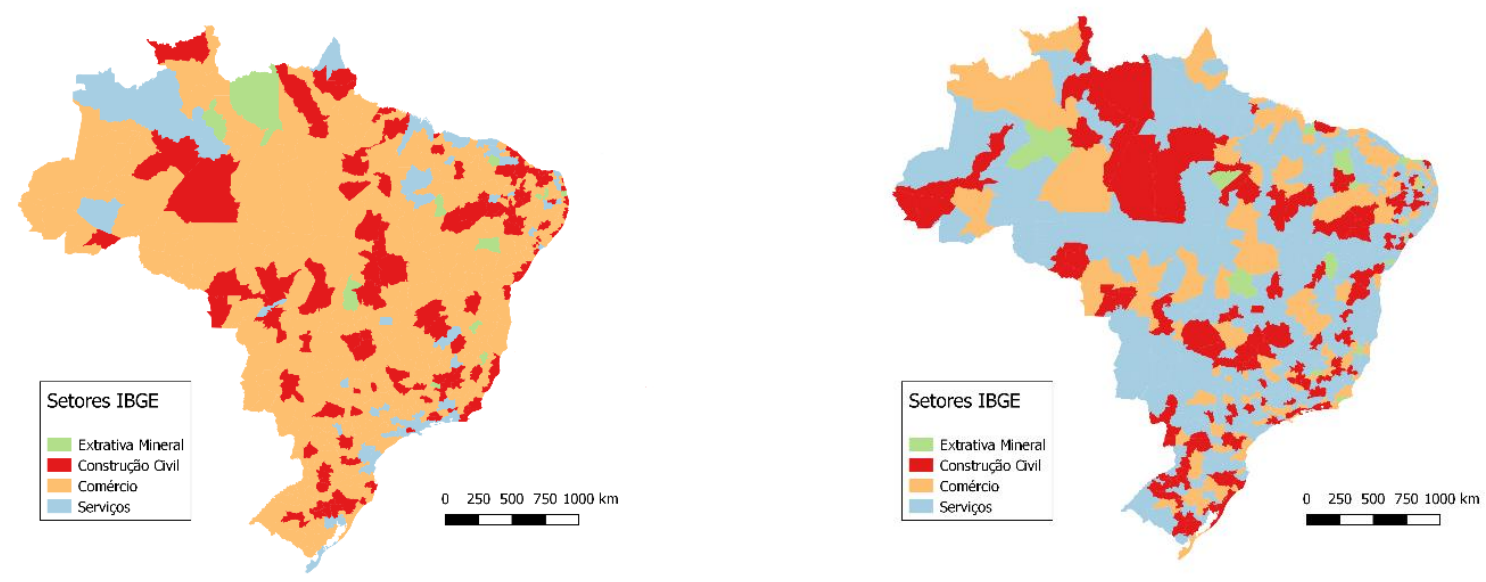

\section{4a. Primeiro Setor}

4b. Segundo setor

Figura 4. Setores com maior variação positiva no Efeito Estrutural (EE) - microrregiões

Fonte: Elaboração própria. 
$\mathrm{Na}$ análise do efeito diferencial, cabe destacar que os setores apresentaram a seguinte ordem de importância: serviços $(35,5 \%$ e 10,8\%), indústria de transformação $(18,6 \%$ e $18,5 \%)$, construção civil (17,4\% e 9,5\%), administração pública (15,1\% e 25,1\%), comércio (9,9\% e 21,5\%), agropecuária, extração vegetal, caça e pesca $(1,6 \%$ e $5,7 \%)$, extrativa mineral $(1,1 \%$ e $4,8 \%)$ e serviços industriais de utilidade pública $(0,9 \%$ e $4,1 \%)$. Ainda, apesar da média do efeito diferencial por classificação de VLT - Tabela 4 mostrar que todas as classificações têm efeito D negativo, apenas 7 microrregiões não apresentaram nenhum setor com efeito diferencial positivo (Amapá, Itajubá, Barbacena, Cataguases, Barra Do Piraí, Marília, Blumenau, Porto Alegre e Campanha Ocidental).

Nota-se ainda que resultados consistentes em favor de determinados setores não são tão claros na análise do efeito diferencial quanto na análise do efeito estrutural, mas existem padrões diferenciados de relevância setorial que são passíveis de destaque quando analisadas regiões federativas. Considerando a soma do percentual de cada setor sendo o primeiro ou segundo na variação positiva e analisando quais setores tiveram percentual por região federativa acima da média nacional, encontramos os seguintes comportamentos:

1. extrativa mineral: sudeste e sul;

2. indústria de transformação: sudeste e sul;

3. serviços industriais de utilidade pública: sul

4. construção civil: norte, nordeste e centro-oeste;

5. comércio: norte e nordeste

6. serviços: norte, nordeste e centro-oeste;

7. administração pública: sul, sudeste e centro-oeste;

8. agropecuária, extração vegetal, caça e pesca: sul, sudeste e centro-oeste.

Como já explicitado, o componente diferencial indica o crescimento da microrregião pelo fato da taxa de crescimento em determinados setores ter sido maior nela do que na média nacional do mesmo setor. Sendo assim, nota-se a relevância de serviços, comércio e construção civil para o desenvolvimento do emprego principalmente no norte e nordeste, justamente os setores de principal crescimento e com grande nível de participação no nível nacional.

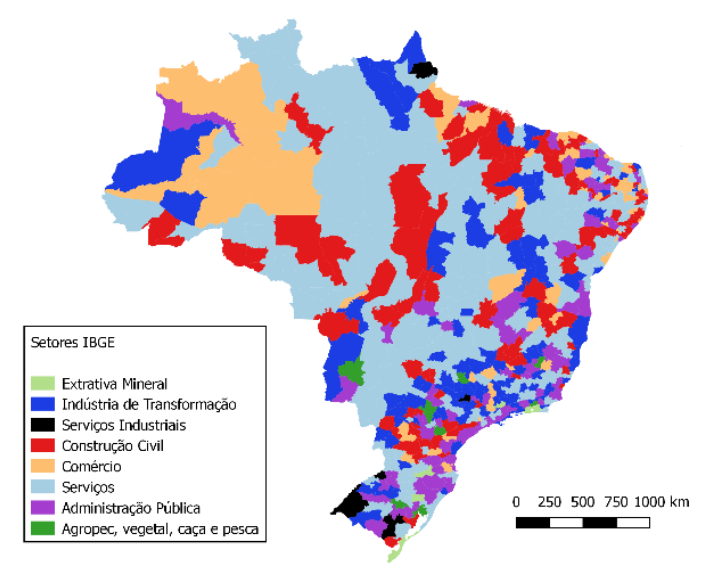

5a. Primeiro Setor

Figura 5. Setores com maior variação positiva no Efeito Diferencial (D) - microrregiões

Fonte: Elaboração própria.

Por último, apresentam-se os mapas nacionais para análise do efeito alocação, no que tange especificamente ao efeito 'vantagem competitiva especializada'; ou seja, no mapa são representados os setores que apresentaram valor positivo para a rubrica especialização e para a rubrica vantagem competitiva. Por conta disso, algumas microrregiões aparecem sem nenhuma representação na Figura 7. É importante salientar que as regiões federativas que tiveram menos microrregiões sem efeito alocação vantagem competitiva especializada positivo foram a região norte, nordeste e centro-oeste. 


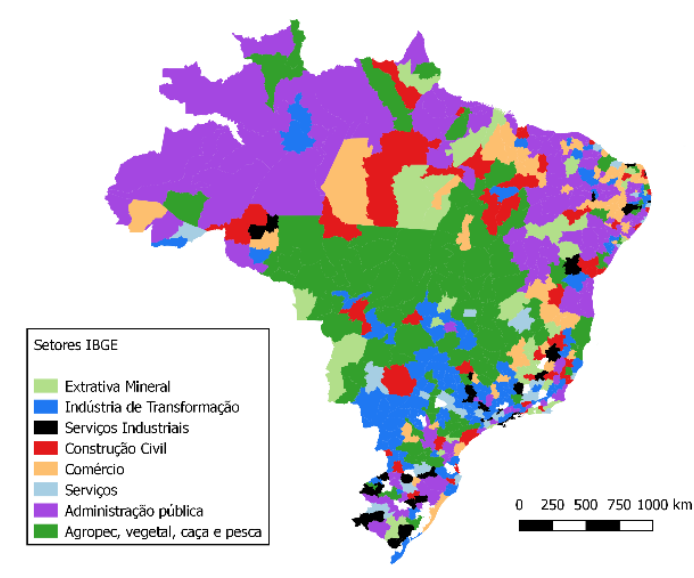

6a. Primeiro Setor

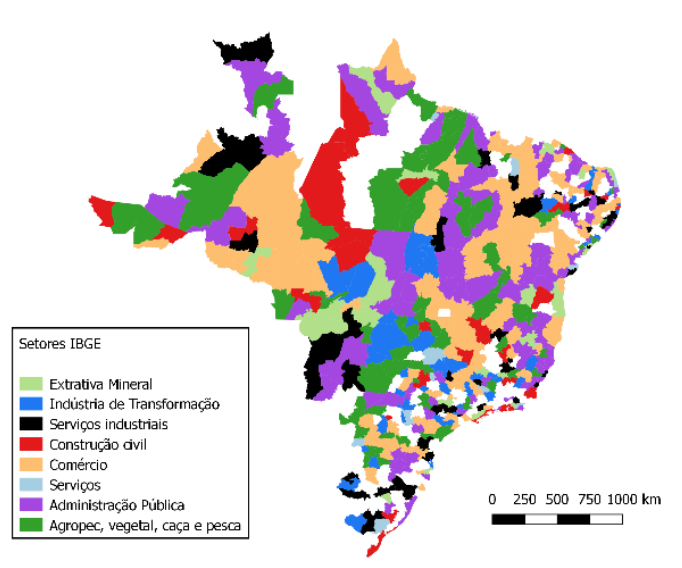

6b. Segundo setor

Figura 6. Setores com maior variação positiva no Efeito Alocação (A) - Vantagem Competitiva Especializada - microrregiões

Fonte: Elaboração própria.

A consideração do efeito alocação com vantagem competitiva especializada significa dizer que estamos considerando apenas o efeito de setores em que as microrregiões são especializadas e que possuem maior vantagem competitiva. Os resultados para o primeiro setor com variação positiva são bastante conclusivos nos casos comparativos de algumas regiões federativas. Por exemplo, o 'setor agropecuária, extração vegetal, caça e pesca' foi responsável pelo estabelecimento do efeito em grande parte da região centro-oeste, com importância elevada também para o oeste mineiro e nas porções sudoeste da região nordeste, na Bahia principalmente. Esses resultados são bastante relacionados ao boom de commodities no mercado internacional (Sessa, Simonato, e Domingues 2017), em específico ao impacto do aumento da fronteira agrícola da soja no Brasil (FREDERICO, 2013).

Ainda, um grupo de microrregiões localizadas no sul da região centro-oeste - principalmente no Mato Grosso do Sul -, no norte do Paraná, no oeste paulista e no triângulo e sul de Minas Gerais apresentam resultados favoráveis para a indústria de transformação. Esses resultados devem estar linkados também à fronteira agrícola da soja e ao papel destacado da indústria alimentícia e de suporte às atividades agrícolas.

A administração pública apresenta relevância para as regiões norte e nordeste, destacando o efeito do aumento do aparato público como um importante definidor do aumento do emprego nessas regiões. Esse aumento deve estar associado às políticas de acesso à educação superior, que elevou o número de instituições federais de ensino principalmente nessas regiões. Esse, porém, não deve ser visto como o único componente desse processo, visto o aumento da qualificação da força de trabalho no período (antes da maturação plena do REUNI). De qualquer forma, maiores estudos são importantes para a análise desse aspecto, o que deve ser feito em futuros trabalhos.

\section{Considerações finais}

O período 2003-2013 é marcado por um processo, a nível nacional, de redução do desemprego e resultados macroeconômicos importantes no que diz respeito a crescimento - PIB - e desenvolvimento econômico - PIB per capita. Apesar disso, é um período entendido por vieses bastante distintos, visto que a base do crescimento foi focada em um comportamento exógeno - a demanda internacional por produtos de baixa intensidade tecnológica, as commodities -, um padrão interno de crescimento orientado pela demanda via políticas de redistribuição de renda e pelo financiamento estatal em projetos de infraestrutura e habitacionais. Associado a isso, uma política de valorização do salário mínimo promoveu um aumento real da remuneração média durante todo o período.

$\mathrm{Na}$ análise dos dados nacionais, os impactos desse processo de crescimento ficam claros no aumento na participação do emprego do setor comércio e construção civil e no declínio do setor indústria de transformação. O problema é que essa modificação da estrutura setorial de emprego é impactada diretamente também pelo perfil salarial dos setores; o setor comércio apresenta o menor salário real médio 
em 2013, o setor construção civil o terceiro menor, e o setor serviços apresenta a segunda menor taxa de crescimento (esse o setor de maior empregabilidade na economia nacional).

Esse trabalho procurou analisar esses resultados à luz das disparidades regionais existentes no território brasileiro, fazendo uma análise da evolução do emprego a nível microrregional. Para tal observação, foi utilizada a metodologia shift-share buscando identificar e desagregar os componentes do crescimento do emprego em uma análise descritiva da estrutura econômica por componentes que destacam o dinamismo setorial na criação de empregos, as vantagens locacionais e a especialização regional em setores que possuem maior vantagem competitiva, compondo todos conjuntamente o índice de Variação Líquida Total (VLT) do emprego.

Em linhas gerais, é verificado um resultado satisfatório para o total das microrregiões nacionais com maior número de microrregiões apresentado resultado de VLT positivo. Considerando as regiões federativas, importante resultado também é obtido quando observado que as regiões norte, nordeste e centro-oeste possuem comparativamente mais microrregiões com VLT positivo, o que indica uma redução da disparidade regional no emprego em comparação às regiões mais desenvolvidas do país, as regiões sul e sudeste.

Adicionalmente, as observações de demais variáveis socioeconômicas desses grupos de microrregiões nos permitem concluir que existe um comportamento de redução de desigualdade de remuneração pelo porte microrregional, com um maior crescimento da remuneração média em microrregiões pequenas e médias. Ainda, um grupo de microrregiões de médio porte - de 150 a 550 mil habitantes - foram as principais beneficiadas na evolução estrutural do emprego no período considerado.

A observação dos distintos efeitos dos componentes do VLT nos mostrou diferentes resultados setoriais. Porém, em resumo, os setores que mais contribuíram para o VLT positivo foram o setor comércio, com ampla vantagem, seguido de serviços, construção civil, indústria de transformação, administração pública, agropecuária, extração vegetal, caça e pesca, extrativa mineral e serviços industrias de utilidade pública. É certo que os diferentes componentes do VLT mostram que as contribuições setoriais foram de perfis distintos, mas os setores comércio, serviços e construção civil aparecem com muita frequência no efeito estrutural e efeito diferencial. Cabe destacar que os resultados são congruentes com os encontrados para período anterior (1991-2003) por Sesso Filho et al (2010), que apresentaram o deslocamento dos postos de trabalho dos setores agropecuário e industrial para o de comércio e serviços. Em suma, essa parece ser uma trajetória com longevidade maior do que o período compreendido nesse artigo.

Ainda, para o efeito alocação com vantagem competitiva especializada notamos a relevância do setor administração pública para as regiões norte e nordeste, do setor agropecuária, extração vegetal, caça e pesca na região centro-oeste, no oeste mineiro e nas porções sudoeste da região nordeste (Bahia principalmente), resultado este conectado ao boom das commodities, em específico à expansão da fronteira agrícola da soja, e indústrias de transformação no sul da região centro-oeste, no norte do Paraná, no oeste paulista e no triângulo e sul de Minas Gerais, resultados esses conexos ao papel destacado da indústria alimentícia e de suporte às atividades agrícolas.

Todos esses resultados devem ser vistos e analisados com parcimônia, visto o alto grau de agregação que a análise impõe quando utiliza a classificação de setores IBGE. De qualquer modo, refletem ganhos no que tange à diminuição da desigualdade regional com o aumento relativo do número de empregos nas regiões norte, nordeste e centro-oeste. De qualquer forma, é latente que esse processo sofra críticas quanto à capacitação de longo prazo, considerando as bases nas quais a diminuição do desemprego se deu: em setores com baixo dinamismo econômico, que não envolvem transbordamentos setoriais e com baixa agregação de valor. Ademais, a redução da representatividade do emprego industrial é um elemento importante para a análise desse processo, uma vez que a indústria é um segmento fundamental para a promoção do desenvolvimento econômico e regional. Nesse sentido, é questionável a sustentabilidade desse processo de aumento no nível de emprego formal nas diversas microrregiões do país, frente a um cenário em que a indústria vem diminuindo sua participação.

Considerando a evolução das capacitações econômicas de uma região dependentes de um aparato interconectado de agentes, instituições, políticas e atores, os resultados destacados no texto não apresentam características que vislumbrem o desenvolvimento econômico de longo prazo. É bem certo que as políticas públicas foram importantes no processo, conforme destacamos a nível nacional para os programas de 
infraestrutura e habitação, além do efeito do dinamismo do setor administração pública nas regiões norte e nordeste, fator esse que está diretamente relacionado à regionalização e aumento do acesso ao ensino superior - e qualificação da força de trabalho - para essas regiões. Essas, contudo, parecem ter sido políticas 'soltas', no sentido de não estarem conectadas a necessidades regionais mais amplas, como políticas de fomento produtivo-econômico bem delineadas e que expandam setores com maior transbordamento e valor agregado (notadamente indústria de transformação e serviços industriais).

Os programas de infraestrutura e habitação promoveram inclusão social, principalmente, mas não podem ser destacadas melhorias consideráveis na infraestrutura produtiva e modais de transporte que permitam, no agregado nacional, redução de custo dos produtos e aumento da competitividade internacional. $\mathrm{O}$ aumento do acesso ao ensino superior caminha junto a esse resultado: tem um perfil social importante, permitindo que pessoas de baixa renda acessem a educação, mas a falta de coordenação de políticas necessárias para o catching-up de um sistema de inovação fez com que o principal resultado desse processo seja uma população mais qualificada empregada em setores de baixo dinamismo.

\section{Referências Bibliográficas}

ARBACHE, J. Produtividade no setor de serviços. In: DE NEGRI, F.; CAVALCANTE, L. R. (Org.). . Produtividade no Brasil: desempenho e determinantes. IPEA ed. Brasília: [s.n.], 2015. p. 568. Disponível em: <http://www.ipea.gov.br/agencia/images/stories/PDFs/livros/livros/prod_brasil_2015_cap-10.pdf>. Acesso em: 28 abr. 2017.

BRASIL. MINISTÉRIO DA EDUCAÇÃO. A democratização e expansão da educação superior no Brasil: 2003-2014. $\quad$ [S.1: $2015 . \quad$ D.n.], <http://portal.mec.gov.br/index.php?option=com_docman\&view=download\&alias=16762-balancosocial-sesu-2003-2014\&Itemid=30192>.

BRESSER-PEREIRA, L. C. The Dutch disease and its neutralization: a Ricardian approach. Brazilian Journal of Political Economy, v. 28, n. 1, p. 47-71, 2008. Disponível em: <http://www.scielo.br/pdf/rep/v28n1/a03v28n1.pdf>. Acesso em: 11 abr. 2017.

CANO, W. A desindustrialização no Brasil. Economia e Sociedade, v. 21, n. 4, p. 831-851, 2012.

CURADO, M. Uma avaliação da economia brasileira no Governo Lula. Economia \& Tecnologia, v. Volume Esp, n. Ano 07, p. 91-104, 2011.

DE PAULI, R. C.; NAKABASHI, L.; SAMPAIO, A. V. Mudança estrutural e mercado de trabalho no Brasil. Revista de Economia Política, v. 32, n. 3, p. 459-478, 2012. Disponível em: <http://www.scielo.br/pdf/rep/v32n3/07.pdf>. Acesso em: 11 abr. 2017.

DINIZ, C. C. Desenvolvimento poligonal no Brasil: nem desconcentração, nem contínua polarização. Nova Economia, v. 3, n. 1, p. 35-64, 1993.

ERBER, F. S. As convenções de desenvolvimento no governo lula: um ensaio de economia política. Revista de Economia Política, v. 31, n. 1, p. 31-55, 2011. Disponível em: <http://www.scielo.br/pdf/rep/v31n1/a02v31n1.pdf>. Acesso em: 18 abr. 2017.

ESTEBAN-MARQUILLAS, J. M. A reinterpretation of Shift-share Analysis. Regional and Urban Economics, v. 2, n. 3, p. 249-261, 1972. Disponível em: 〈http://esteban.iae-csic.org/pdf/Shift_Share1.pdf〉. Acesso em: 10 abr. 2017.

FILHO, F. F.; PAULA, L. F. Padrões de crescimento e desenvolvimentismo : uma perspectiva keynesianoinstitucionalista. Nova Economia, v. 26, n. 3, p. 775-807, 2016.

FREDERICO, S. Agricultura científica globalizada e fronteira agrícola moderna no Brasil. Revista FrancoBrasileira de Geografia, v. 17, 2013. Disponível em: <https://confins.revues.org/8153?lang=pt\#text>.

GONÇALVES, R. Governo Lula e o nacional- desenvolvimentismo às avessas. Soc Bras Economia Politica, v. $\quad 31, \quad$ p. $\quad 5-30, \quad 2012 . \quad$ Disponível em: 
<http://www.ie.ufrj.br/intranet/ie/userintranet/hpp/arquivos/260220162201_Texto3Reinaldoseminario.pdf >. Acesso em: 18 abr. 2017.

HAUSMANN, R. et al. The Atlas of Economic Complexity - Mapping Paths to Prosperity. [S.1: s.n.], 2011. Disponível

<file:///Users/edwardcrowley/Downloads/HarvardMIT_AtlasOfEconomicComplexity_Part_I.pdf\%5Cnpa pers3://publication/uuid/50DF1AB5-ACE1-45B3-BF9C-5E6F799630E5>.

JACINTO, P. DE A.; RIBEIRO, E. P. Crescimento Da Produtividade No Setor De Serviços E Da Indústria No Brasil: Dinâmica E Heterogeneidade. Economia Aplicada, v. 19, n. 3, p. 401-427, 2015. Disponível em: <http://www.scielo.br/scielo.php?script=sci_arttext\&pid=S1413-80502015000300401\&lang=pt>.

KALDOR, N. A Model of Economic Growth. The Economic Journal, v. 67, n. 268, p. 591-624, 1957. Disponível em: <http://www.jstor.org/stable/2227704>. Acesso em: 20 abr. 2017.

MARINHO, E. L. L.; NOGUEIRA, C. A. G.; ROSA, A. L. T. Evidências Empíricas da Lei de KaldorVerdoorn para a Indústria de Transformação do Brasil (1985-1997) *. Revista Brasileira de Economia, v. 56, n. 3, p. 457-482, 2002. Disponível em: 〈http://www.scielo.br/pdf/rbe/v56n3/a04v56n3.pdf>. Acesso em: 20 abr. 2017.

MORRONE, H. Estimação da Lei de Kaldor- Estimação da Lei de Kaldor-Verdoorn para a indústr Verdoorn para a indústr Verdoorn para a indústria brasileira ia brasileira no período no período 2001-12. Indic. Econ. FEE, v. 41, n. 1, p. 75-86, 2013.

OREIRO, J. L.; FEIJÓ, C. A. Desindustrialização: conceituação, causas, efeitos e o caso brasileiro. Revista de Economia Política, v. 30, n. 2, p. 219-232, 2010. Disponível em: <http://www.scielo.br/pdf/rep/v30n2/03.pdf>. Acesso em: 11 abr. 2017.

PINHO, I. R.; ZAN, D. D. P. E. Plano nacional de Educação (PNE): Questões Desafiadoras e Embates Emblemáticos. 1. ed. Brasília: INEP, 2013.

REMY, M. A.; QUEIROZ, S.; FILHO, L. A. DA S. E VOLUÇÃO RECENTE DO EMPREGO FORMAL NO B RASIL : 2000-2008. Revista ABET, v. X, n. 1, p. 57-78, 2011.

RESENDE, G. M. et al. Brasil: Dez anos da Política Nacional de Desenvolvimento Regional (PNDR). Boletim urbano, regional e ambiental: IPEA, v. 11, p. 29-35, 2015. Disponível em: <http://repositorio.ipea.gov.br/bitstream/11058/4866/1/BRU_n11_brasil.pdf>. Acesso em: 11 abr. 2017.

ROWTHORN, R.; RAMASWAMY, R. Growth, Trade and Deindustrialization., IMF Working Paper., $\mathrm{n}^{\circ}$ WP/98/60. New $\quad$ York: $\quad$ [s.n.], $1998 . \quad$ Disponível em: <https://www.imf.org/external/pubs/ft/wp/wp9860.pdf>. Acesso em: 12 abr. 2017.

SABOIA, J. A continuidade do processo de desconcentração regional da indústria brasileira nos anos 2000. Nova Economia, v. 23, n. 2, p. 219-278, 2013.

SANTOS, U. P. DOS. Distribución espacial de los entes del sistema nacional de innovación brasileño: análisis de la década de 2000. Revista de la Cepal, v. 121, 2017.

SESSA, C. B.; SIMONATO, T. C.; DOMINGUES, E. P. O ciclo das Commodities e crescimento regional desigual no Brasil: uma aplicação de equilíbrio geral computável (EGC). , TD., $\mathrm{n}^{\circ}$ 551. Belo Horizonte: [s.n.], 2017. Disponível em: <http://www.cedeplar.ufmg.br/pesquisas/td/TD 551.pdf>. Acesso em: 20 abr. 2017.

SESSO FILHO, U. A. et al. Decomposição estrutural da variação do emprego no Brasil, 1991-2003. Economia Aplicada, v. 14, n. 1, p. 99-123, 2010. Disponível em: <http://www.scielo.br/pdf/ecoa/v14n1/a07v14n1.pdf>. Acesso em: 5 abr. 2017.

SILVEIRA NETO, R.; AZZONI, C. Os programas sociais e a recente queda na desigualdade regional da renda no Brasil. In: CAMPELLO, T.; NERI, M. (Org.). . Bolsa Família: uma década de inclusão e cidadânia. Brasilia: IPEA, 2013. p. 217-232. 
SIMÕES, R. Métodos de Análise Regional e Urbana: diagnóstico aplicado ao planejamento. , $\mathrm{n}^{0} \mathrm{TD}$ Cedeplar 259. Belo Horizonte: [s.n.], 2005. Disponível em: <https://core.ac.uk/download/pdf/6519931.pdf>. Acesso em: 10 abr. 2017.

SOUZA, N. J. Desenvolvimento Regional. São Paulo: Atlas, 2009.

VERDOORN, P. J. Ccomplementarity and Long-range Projections. Econometrica, v. 24, n. 4, p. 429-450, 1956.

VERDOORN, P. J. Verdoorn's Law in Retrospect: A Comment. The Economic Journal, v. 90, n. 358, p. 382-385, 1980. Disponível em: <http://www.jstor.org/stable/2231798>. Acesso em: 20 abr. 2017.

\section{Anexos}

Tabela A1 - Microrregiões segundo grupo de VLT

\begin{tabular}{|c|c|c|c|c|c|}
\hline Grupo 1 & Grupo 2 & Grupo 3 & Grupo 4 & Grupo 5 & Grupo 6 \\
\hline Teresina & Almeirim & Colorado do oeste & Guajará-mirim & Ji-paraná & Porto velho \\
\hline Chorozinho & Paragominas & Japurá & Tarauacá & Alvorada doeste & Ariquemes \\
\hline Litoral nordeste & Rio formoso & Belém & Sena Madureira & Cruzeiro do sul & Cacoal \\
\hline Natal & Porto nacional & Itaituba & Brasiléia & Rio negro-am & Vilhena \\
\hline Litoral sul-rn & Médio mearim & Miracema do tocantins & Tefé & Juruá & Rio branco \\
\hline Mata setentr pernambucana & Codó & Pindaré & Coari & Rio preto da eva & Alto solimões \\
\hline Mata merid pernambucana & Cascavel-ce & Caxias & Itacoatiara & Parintins & Manaus \\
\hline Serrana dos quilombos & Vale do açu & Chapadas do alto itapecuru & Madeira & Boca do acre & Boa vista \\
\hline Mata alagoana & Agreste potiguar & Pio ix & Nordeste de Roraima & Purus & Santarém \\
\hline São miguel dos campos & Itabaiana & Uruburetama & Portel & Caracaraí & Castanhal \\
\hline Aracaju & João pessoa & Canindé & Salgado & Sudeste de roraima & Bragantina \\
\hline Salvador & Pajeú & Sertão de cratéus & Conceição do Araguaia & Óbidos & Cametá \\
\hline Ilhéus-itabuna & Médio capibaribe & Litoral de aracati & Oiapoque & Furos de breves & Tomé-açu \\
\hline Sete lagoas & Penedo & Serra do pereiro & Amapá & Arari & Altamira \\
\hline Belo horizonte & Japaratuba & Caririaçu & Mazagão & Guamá & São félix do xingu \\
\hline Governador valadares & Juazeiro & Barro & Gurupi-to & Tucuruí & Parauapebas \\
\hline Ipatinga & Paulo afonso & Serra de são miguel & Rosário & Bico do papagaio & Marabá \\
\hline São sebastião do paraíso & Itapetinga & Pau dos ferros & Lençois maranhenses & Jalapão & Redenção \\
\hline Varginha & Pirapora & Umarizal & Baixada maranhense & Dianópolis & Macapá \\
\hline Poços de caldas & Almenara & Angicos & Itapecuru mirim & Litoral ocidental maranhense & Araguaína \\
\hline São lourenço & Uberaba & Borborema potiguar & Coelho neto & Gurupi-ma & Aglomeração de são luís \\
\hline Itajubá & Curvelo & Macaíba & Litoral piauiense & Presidente dutra & Imperatriz \\
\hline Barbacena & Caratinga & Piancó & Médio parnaíba piauiense & Baixo parnaíba maranhense & Alto mearim e grajaú \\
\hline Juiz de fora & Aimorés & Seridó ocidental paraibano & Valença do Piauí & Chapadinha & Gerais de balsas \\
\hline Cataguases & Alfenas & Seridó oriental paraibano & Bertolínia & Porto franco & Baixo parnaíba piauiense \\
\hline Três rios & Santa rita do sapucaí & Cariri ocidental & Meruoca & Chapadas das mangabeiras & Alto parnaíba piauiense \\
\hline Nova friburgo & Ponte nova & Cariri oriental & Sobral & Campo maior & Picos \\
\hline Vale do paraíba fluminense & Colatina & Curimataú oriental & Ipu & Floriano & Litoral de camocim e acaraú \\
\hline Barra do piraí & São mateus & Brejo paraibano & Itapipoca & Alto médio gurguéia & Baixo curu \\
\hline Serrana & Linhares & Sapé & Sertão de inhamuns & São raimundo nonato & Fortaleza \\
\hline Macacu-caceribu & Itaperuna & Alagoas sertão são francisco & Sertão de senador pompeu & Chapadas extr sul piauiense & Cariri \\
\hline Rio de janeiro & Santo ant de pádua & Santana do ipanema & Médio Jaguaribe & Alto médio canindé & Campina grande \\
\hline Jales & Campos goytacazes & Batalha & Iguatu & Ibiapaba & Araripina \\
\hline São joaquim da barra & Cantagalo-cordeiro & Palmeira dos índios & Várzea alegre & Coreaú & Petrolina \\
\hline Franca & Santa maria madalena & Propriá & Lavras da mangabeira & Santa quitéria & Vale do ipojuca \\
\hline Jaboticabal & Vassouras & Baixo cotinguiba & Chapada do Araripe & Médio curu & Alto capibaribe \\
\hline Andradina & Catanduva & Boquim & Brejo santo & Baturité & Garanhuns \\
\hline Birigui & Amparo & Livramento do brumado & Chapada do apodi & Pacajus & Vitória de santo antão \\
\hline Jaú & Tupã & Salinas & Médio oeste & Sertão de quixeramobim & Itamaracá \\
\hline Botucatu & Assis & Grão mogol & Macau & Baixo jaguaribe & Recife \\
\hline Araraquara & Ourinhos & Bocaiúva & Serra de Santana & Mossoró & Suape \\
\hline São carlos & Itapeva & Diamantina & Seridó ocidental & Seridó oriental & Arapiraca \\
\hline Pirassununga & Itapetininga & Capelinha & Baixa verde & Cajazeiras & Maceió \\
\hline São joão da boa vista & Capão bonito & Pedra azul & Catolé do rocha & Sousa & Barreiras \\
\hline Moji mirim & Campos do jordão & Nanuque & Serra do Teixeira & Patos & Senhor do bonfim \\
\hline Presidente prudente & São josé dos campos & Ituiutaba & Curimataú ocidental & Itaporanga & Irecê \\
\hline Marília & Guaratinguetá & Três marias & Esperança & Litoral norte & Feira de santana \\
\hline Piedade & Bananal & Pará de minas & Guarabira & Itaparica & Alagoinhas \\
\hline Bragança paulista & Paraibuna/paraitinga & Guanhães & Umbuzeiro & Sergipe sertão são francisco & Santo antônio de jesus \\
\hline Osasco & Registro & Peçanha & Litoral sul-pb & Nossa senhora das dores & Guanambi \\
\hline Itapecerica da serra & Campo mourão & Formiga & Salgueiro & Agreste de itabaiana & Brumado \\
\hline São paulo & Porecatu & Passos & Sertão do moxotó & Tobias barreto & Vitória da conquista \\
\hline Mogi das cruzes & Ivaiporã & Andrelândia & Vale do ipanema & Cotegipe & Porto seguro \\
\hline Santos & Assaí & Lavras & Brejo pernambucano & Santa maria da vitória & Montes claros \\
\hline Londrina & Jacarezinho & São joão del rei & Fernando de noronha & Bom jesus da lapa & Uberlândia \\
\hline Cornélio procópio & Ibaiti & Viçosa & Serrana do sertão alagoano & Jacobina & Frutal \\
\hline Telêmaco borba & Guarapuava & Muriaé & Traipu & Itaberaba & Itabira \\
\hline Jaguariaíva & Lapa & Auriflama & Litoral norte alagoano & Euclides da cunha & Ouro preto \\
\hline Ponta grossa & Curitibanos & Barretos & Carira & Ribeira do pombal & Pouso alegre \\
\hline Palmas & Rio do sul & Batatais & Agreste de lagarto & Serrinha & Vitória \\
\hline União da vitória & Três passos & Lins & Cotinguiba & Seabra & Guarapari \\
\hline Paranaguá & Erechim & Avaré & Estância & Jequié & Macaé \\
\hline Joaçaba & Santo ângelo & Goioerê & Barra & Paracatu & Bacia de são joão \\
\hline Canoinhas & ljuí & Floraí & Jeremoabo & Janaúba & Lagos \\
\hline São bento do sul & Soledade & Faxinal & Entre rios & Patos de minas & Itaguaí \\
\hline Campos de lages & Guaporé & Pitanga & Catu & Conceição do mato dentro & Votuporanga \\
\hline Blumenau & Santiago & Prudentópolis & Boquira & Itaguara & São josé do rio preto \\
\hline Vacaria & Santa maria & Irati & Valença & Conselheiro lafaiete & Ribeirão preto \\
\hline Caxias do sul & Restinga seca & Cerro azul & Unaí & Divinópolis & Bauru \\
\hline
\end{tabular}




\begin{tabular}{|c|c|c|c|c|c|}
\hline Santa cruz do sul & Cachoeira do sul & Rio negro-pr & Januária & Manhuaçu & Campinas \\
\hline Lajeado-estrela & São jerônimo & Concórdia & Araçuaí & Afonso cláudio & Tatuí \\
\hline Montenegro & Camaquã & Cerro largo & Teófilo otoni & Santa teresa & Sorocaba \\
\hline Gramado-canela & Campanha central & Carazinho & Patrocínio & Alegre & Jundiaí \\
\hline Porto alegre & Campanha meridional & Cruz alta & Araxá & Baía da ilha grande & Caraguatatuba \\
\hline Campanha ocidental & Serras de sudeste & Sinop & Bom despacho & Fernandópolis & Franco da rocha \\
\hline Pelotas & Jaguarão & Rosário oeste & Mantena & Nhandeara & Guarulhos \\
\hline Campo grande & Baixo pantanal & Rio vermelho & Piuí & Araçatuba & Umuarama \\
\hline \multirow[t]{32}{*}{ Brasília } & Aquidauana & & Campo belo & Rio claro & Maringá \\
\hline & & & Oliveira & Limeira & Cascavel-pr \\
\hline & & & Ubá & Piracicaba & Foz do iguaçu \\
\hline & & & Barra de são francisco & Dracena & Francisco beltrão \\
\hline & & & Nova venécia & Adamantina & Pato branco \\
\hline & & & Montanha & Itanhaém & Chapecó \\
\hline & & & Cachoeiro de itapemirim & Paranavaí & Joinville \\
\hline & & & Itapemirim & Cianorte & Itajaí \\
\hline & & & Novo horizonte & Astorga & Tijucas \\
\hline & & & Ituverava & Apucarana & Florianópolis \\
\hline & & & Toledo & Wenceslau braz & Criciúma \\
\hline & & & Capanema & São miguel do oeste & Passo fundo \\
\hline & & & São mateus do sul & Xanxerê & Osório \\
\hline & & & Curitiba & Ituporanga & Três lagoas \\
\hline & & & Tabuleiro & Tubarão & Dourados \\
\hline & & & Santa rosa & Araranguá & Alta floresta \\
\hline & & & Sananduva & Frederico westphalen & Colíder \\
\hline & & & Não-me-toque & Litoral lagunar & Parecis \\
\hline & & & Alto taquari & Cassilândia & Alto teles pires \\
\hline & & & Paranaíba & Iguatemi & Norte araguaia \\
\hline & & & Nova andradina & Aripuanã & Cuiabá \\
\hline & & & Bodoquena & Arinos & Primavera do leste \\
\hline & & & Médio araguaia & Paranatinga & Ceres \\
\hline & & & Alto paraguai & Canarana & Anápolis \\
\hline & & & Alto pantanal & Alto guaporé & Goiânia \\
\hline & & & Tesouro & Tangará da serra & Entorno de brasília \\
\hline & & & Aragarças & Jauru & Sudoeste de goiás \\
\hline & & & Porangatu & Rondonópolis & Vale do rio dos bois \\
\hline & & & Chapada dos veadeiros & Alto araguaia & Meia ponte \\
\hline & & & Iporá & São miguel do araguaia & Catalão \\
\hline & & & Anicuns & Vão do paranã & Quirinópolis \\
\hline & & & Pires do rio & & \\
\hline
\end{tabular}

Fonte: Elaboração própria. 